Ger J Exerc Sport Res 2018 • 48:136-144 https://doi.org/10.1007/s12662-017-0489-5 Received: 8 October 2017

Accepted: 21 December 2017

Published online: 15 January 2018

(c) The Author(s) 2018. This article is an open access publication.

CrossMark

\author{
Christian Thiel ${ }^{1}$ (D) $\cdot$ Klaus Pfeifer $^{2} \cdot$ Gorden Sudeck $^{3}$ \\ 'Department of Applied Health Sciences, Physiotherapy studies, University of Applied Sciences Bochum, \\ Bochum, Germany \\ ${ }^{2}$ Institute of Sport Science and Sport, University of Erlangen-Nuremberg, Erlangen, Germany \\ ${ }^{3}$ Institute of Sport Science, University of Tübingen, Tübingen, Germany
}

\title{
Pacing and perceived exertion in endurance performance in exercise therapy and health sports
}

\section{A competence-oriented view}

\section{Electronic supplementary material}

The online version of this article (https://doi. org/10.1007/s12662-017-0489-5) contains supplementary material, which is available to authorized users.

\section{Introduction}

When humans travel over a long distance using their own resources, they choose a pace that enables them to reach the goal of locomotion with a self-chosen degree of physiological strain and without threatening their health. This regulation of performance is generally termed pacing.

Pacing requires the integration of anticipation (feed-forward) with physiological signals (feedback) and is particularly apparent in endurance sports: Athletes tailor their metabolic strain, based on their experience and depending on the situation, to temporal or spatial goals (Ulmer, 1996). Pacing also plays a vital role in everyday physical activity, and in the prevention and rehabilitation of lifestyle diseases (Edwards \& Polman, 2013; Smits, Pepping, \& Hettinga, 2014).

The term pacing has been interpreted in a number of ways, as demonstrated in the following paraphrased reviews. Pacing is, therefore,
- ... as originally used in enduranceoriented competitive sports, the efficient utilization of energetic resources during competition, so that all available energy stores are depleted shortly before the finish line, while no considerable reduction of speed occurs (Roelands, de Koning, Foster, Hettinga, \& Meeusen, 2013).

- ... in expanded contexts, the goaldirected management of performance and effort in the course of a longlasting physical activity. Pacing is the strategy of individuals, both highly active and physically inactive, to manage physical and mental performance and effort in relation to a specific goal, understanding the presumable demands of the task (Edwards \& Polman, 2013).

- ... independent of context, the behavioral expression of a continuously running decision process during the regulation of physical performance (Smits et al., 2014).

The term pacing relates to the process of goal-directed management of human resources during physical activity (including both the mechanisms and the organization of the regulation of performance; Edwards \& Polman, 2013; Smits et al., 2014; St Clair Gibson et al., 2013) as well as to the result of this management, namely, a profile of the intensity of human work (i.e., physical activity) over time (Abbiss \& Laursen, 2008). This intensity profile usually relates to the speed of movement (Abbiss \& Laursen, 2008; March, Vanderburgh, Titlebaum, \& Hoops, 2011; Tucker, Lambert, \& Noakes, 2006), but at times it may relate to the delivered mechanical, physiological, or volitional performance (Bernard et al., 2009; Edwards \& Polman, 2013; Le Meur et al., 2009; St Clair Gibson et al., 2013). Pacing in endurance sports may be influenced by a variety of factors, such as duration (Abbiss \& Laursen, 2008), mode of competition (Thiel, Foster, Banzer, \& de Koning, 2012), emotions and affective response (Baron, Moullan, Deruelle, \& Noakes, 2011), deception and false feedback (Jones et al., 2013), as well as performance level, age and/or sex of the athlete, and environmental conditions (Thiel, de Koning, \& Foster, 2015).

In performance-oriented sports, the term pacing strategy has been used to denote a recurring, characteristic sportsand discipline-specific pattern of distributing energetic resources over the course of a competition, demonstrated in the temporal course of speed or power output (Abbiss \& Laursen, 2008). There are different types of pacing strategies. Positive strategies, for example, relate to the controlled reduction of performance over the course of a bout of physical 
activity. Negative strategies refer to the controlled increase of performance over the course of a bout of physical activity, while variable strategies include fluctuations in performance without an immediately recognizable pattern. These fluctuations may arise from preplanned or spontaneous responses to changes of the pace of an opponent, the level of perceived exertion, or the ambient conditions.

The growing topicality and relevance of pacing is demonstrated in the increasing number of international publications on pacing in competitive sports. However, pacing in physical activity in everyday life, as well as in the prevention and rehabilitation of lifestyle diseases, is less frequently considered in the national and international literature.

Pacing is observed in all endurance performance contexts (Edwards \& Polman, 2013; Smits et al., 2014), such as locomotion and transportation, workplace (Ulmer, 1996), and leisure and health (Ekkekakis, 2009). Performance is regulated in regard to the relationship between investment and reward, where investment refers to energetic expenditure, physical fatigue, and perceived risks, and reward refers to the likelihood to reach the intended goals and effects.

In contexts other than competitive sports, the goal is usually not to maximize the speed of locomotion or to deplete physical resources, but to find an individually appropriate pace and level of effort. The anticipatory regulation of physical performance is as relevant for a 65-yearold woman with chronic obstructive pulmonary disease (COPD) who carries her purchases to her flat on the fourth floor (Castro et al., 2013) as for an overweight skilled worker using heavy tools all day at high ambient temperatures or for a patient with multiple sclerosis doing the six-minute walking test (Burschka et al., 2012).

All these tasks, if performed in the usual manner under the given circumstances, induce considerable cardiorespiratory, metabolic, and neuromuscular stress in the individuals carrying them out. A lack of regulation would potentially threaten health, inducing strong physical discomfort (Ekkekakis, Parfitt,
\& Petruzzello, 2011) and/or slowing down or otherwise impairing the completion of this task or following tasks due to fatigue.

Thus, endurance-related physical activity in the prevention (that is, sports for health) and rehabilitation (that is, exercise therapy) of lifestyle diseases also requires pacing. Promoting adequate pacing in health sports and exercise therapy would facilitate increased competence orientation in these contexts (Sudeck \& Pfeifer, 2016) as recommended by health insurances and social pension funds (Deutsche Rentenversicherung, 2016), and empower and strengthen autonomy in terms of patient and client orientation.

The current paper aims to initiate a discussion on the role of pacing in the context of endurance performance in sports for health and exercise therapy. First, pacing will be explained in relation to fatigue and sense of exertion, and then the role of pacing in optimizing health effects and minimizing risks will be discussed, using examples from cardiac prevention and rehabilitation. Next, the relationship between pacing, sense of exertion, and affective condition will be explored, and determinants and approaches for the acquisition of competence will be presented. Finally, application potential and further research requirements will be outlined.

\section{Fatigue and perceived exertion as a basis for pacing}

Perceptions of fatigue and exertion play an important role in endurance-oriented physical activity and exercise training. Muscular fatigue is the exercise-induced reduction in the ability of a muscle to produce strength or power, independent of whether or not the currently executed movement task can be continued (Enoka \& Duchateau, 2008). In a fatigued state, a higher subjective effort may be necessary to produce the same performance (Davis \& Bailey, 1997).

The supraspinal sensation and appraisal of fatigue enables the foresightful dosing of the current performance and prevent excessive peripheral fatigue when considering the remaining physical work (anticipation of the endpoint of a motor task) and ambient conditions (Knicker, Renshaw, Oldham, \& Cairns, 2011; Weir, Beck, Cramer, \& Housh, 2006). Perceptions related to fatigue are continuously used to estimate the effect of the intensity of the momentary exercise on the future performance capability and to adapt the intensity if necessary (St Clair Gibson et al., 2006).

According to Borg, the sum of the situationally relevant peripheral fatigue signals, combined with feelings of physical stress and effort, can be verbalized and measured as the rating of perceived exertion (RPE; Borg, 1970). Findings from high performance sports show that the rating of perceived exertion will usually increase linearly until the finish, provided that an even pacing strategy is being used under standardized conditions (Faulkner, Parfitt, \& Eston, 2008).

Pacing is based on [1] the sense of exertion as the perception of current fatigue, but it goes far beyond that (Tucker, 2009). It also includes the following:

- [2] The conscious choice or subconscious preference of a desired or maximally tolerated level of effort to reach the intended goal: "I do not feel very motivated today, so I would rather put in a moderate effort."

- [3] The anticipation of the remaining physical work (feed-forward mechanism): "I still have two laps in the park to go."

- [4] The estimation of the current physical capacity: "I have been able to practice a lot in the last months, so my aerobic fitness level should be relatively good."

- [5] The consideration of experiences with the completion of the same or somewhat similar exercise task: "Right now, with two of four laps finished, I feel similarly stressed as in the last training bout, which I completed without a problem."

- [6] The choice of keeping or changing the momentary physical performance based on Points [1] to [5] above: "Right now, I have finished half of my training distance. The exercise feels fairly light (Borg 11). Considering my previous experience and estimating my aerobic fitness, this is how I had expected it to be at this point. I will 
Ger J Exerc Sport Res 2018 · 48:136-144 https://doi.org/10.1007/s12662-017-0489-5

(c) The Author(s) 2018. This article is an open access publication.

\section{Thiel · K. Pfeifer · G. Sudeck}

\section{Pacing and perceived exertion in endurance performance in exercise therapy and health sports. A competence-oriented view}

\section{Abstract}

When humans are physically active for an extended period of time, they regulate their physical performance in order to achieve the intended goal of that activity with an individually adequate effort. This permanent conscious or subconscious proportioning of energetic reserves towards an endpoint is termed as "pacing". While pacing has primarily attracted notice in endurance sports competition, it also plays a vital role in other contexts of physical activity, such as locomotion or transport, work, leisure, and prevention and rehabilitation. The current paper outlines some of the fundamentals of pacing and aims to stimulate a debate by highlighting the potential and limitations of a stronger consideration of pacing in exercise therapy and health sports from a biomedical and psychosocial perspective. Endurance training that focuses on the learning of pacing and the perception of exertion may improve the control competence as one component of physical-activity-related health competence. In terms of client orientation, this would strengthen participants' autonomy in exercise configuration, and it might positively influence well-being, self-responsibility, compliance, and long-term training effects. In fact, professional societies see scope for defined target groups in cardiac prevention and rehabilitation to self-regulate their training intensity based on perceived exertion.
However, the training effects and the risks of self-regulation have yet to be investigated more carefully in subjects who are not experienced with exercise. Further research is also needed on the mechanisms of perception of physiological strain and effort, as well as on approaches for optimal support of the learning of pacing to achieve control competence.

Keywords Endurance training $\cdot$ Perception of effort $\cdot$ Selfregulated training $\cdot$ Physical activity-related health competence

\section{Pacing und Beanspruchungsempfinden bei Ausdauerbelastungen in Bewegungstherapie und Gesundheitssport. Eine kompetenzorientierte Betrachtung}

\section{Zusammenfassung}

Wenn Menschen über längere Zeit körperlich aktiv sind, regulieren sie ihre körperliche Leistung, um das intendierte Ziel der Aktivität mit einem individuell angemessenen Aufwand zu erreichen. Diese auf einen Endpunkt bezogene Einteilung energetischer Reserven wird "Pacing" genannt und läuft - bewusst oder unterbewusst - permanent ab. Wenngleich es vor allem im ausdauersportlichen Wettkampf Beachtung findet, spielt Pacing auch in anderen Kontexten der körperlichen Aktivität eine wichtige Rolle, unter anderem in Fortbewegung oder Transport, Arbeit, Freizeit sowie Prävention und Rehabilitation. Der vorliegende Beitrag behandelt einige Grundlagen des Pacings und möchte eine Diskussion anregen, indem Potenzial und Limitationen einer stärkeren Berücksichtigung von Pacing in Gesundheitssport und Bewegungstherapie aus biomedizinischer und psychosozialer Perspektive beleuchtet werden. Ausdauertraining, das auf das Erlernen von Pacing und die Wahrnehmung von Beanspruchung fokussiert, kann die Steuerungskompetenz als Komponente der bewegungsbezogenen Gesundheitskompetenz verbessern. Dies würde im Sinne der Patienten- bzw. Klientenorientierung die Autonomie der Teilnehmer bei der Belastungsgestaltung stärken und könnte Wohlbefinden, Eigenverantwortung, Compliance und langfristige Trainingseffekte günstig beeinflussen. Tatsächlich sehen Fachgesellschaften mittlerweile Spielräume für definierte Zielgruppen in der kardialen
Prävention und Rehabilitation, die Trainingsintensität anhand des Anstrengungsempfindens selbst zu steuern. Welche Trainingseffekte und Risiken diese Selbststeuerung für Menschen ohne Trainingserfahrung mit sich bringt, müsste allerdings noch sorgfältiger untersucht werden. Forschungsbedarf besteht auch zu Mechanismen der Wahrnehmung von Beanspruchung und Anstrengung sowie hinsichtlich möglicher Ansätze zur optimalen Unterstützung des Erlernens von Pacing zur Erlangung von Steuerungskompetenz.

\section{Schlüsselwörter}

Ausdauertraining · Anstrengungsempfinden . Selbstgesteuertes Training • Bewegungsbezogene Gesundheitskompetenz maintain my running speed so that I will feel only moderately exerted at the end of this training bout."

Thus, the actually generated physical performance is the obvious, objectively measurable result of psychophysiological decision processes. These processes may or may not take place consciously, and can be verbalized as in the examples above if conscious. As shown in the following section, this does not occur only in high performance sports but also in health sports and exercise therapy.

\section{Self-regulation of exercise intensity in cardiac prevention and rehabilitation}

Physiological signals such as the perception of effort, fatigue, or pain during acute performance should also enable individuals with little experience in sports and patients in rehabilitation programs to es- timate and manage their exercise intensity in a health-competent way, so that it results in an individually adequate stimulus. According to the subcomponent "control competency" of physical-activity-related health competency, the strain would be individually adequate if it would enable and ensure the following:

a) the optimization of effects

b) the minimization of health risks

c) a positive affective response 
or at least increase the probability for these to occur (Sudeck \& Pfeifer, 2016). Regarding the three aspects listed above, previous recommendations for exercise in cardiac prevention and rehabilitation primarily relate to perceived exertion (see Point [1] above) as an elementary part of adequate pacing behavior. In contrast, the further constituents of pacing (see Points [2] to [6] above) have rarely been studied in this context.

\section{Optimization of health effects}

Training interventions in cardiac rehabilitation are often performed as a continuous endurance exercise at an intensity of about $40-80 \%$ of maximum aerobic capacity, resulting in mean improvements of aerobic capacity by $13-66 \%$ within 4-26 weeks (Hansen, Dendale, Berger, \& Meeusen, 2005). Following recommendations by the American College of Sports Medicine (ACSM), patients with a stable heart disease should exercise at a "fairly light" to "somewhat hard" level (Borg-RPE 11-14; American College of Sports Medicine, Thompson, Gordon, \& Pescatello, 2010).

In the primary prevention of cardiac disease, assuming the same total energy expenditure, a higher intensity leads to larger effects than lower intensities do (Thiel, Vogt, \& Banzer, 2012). Relating to secondary prevention, there is a lack of multi-arm prospective studies on the intensity-response relationship (Bjarnason-Wehrens et al., 2009b). Training effects do vary considerably between individuals (Timmons, 2011), and it is unclear which individuals and patient groups will respond to endurance training with larger or smaller health effects (Bjarnason-Wehrens et al., 2009b).

The effects of purely self-regulated training on adherence, aerobic capacity, and health-related endpoints have rarely been studied. A preliminary randomized controlled study (Ilarraza, Myers, Kottman, Rickli, \& Dubach, 2004) observed patients after myocardial infarction or bypass surgery who determined their training intensity completely by themselves using the rating of perceived exertion ("slightly strenuous"). At the same amount of training
$(5 \times 30$ min cycle ergometer per week plus $2 \times 45$ min walking per day), they improved their aerobic capacity within 30 days by approximately the same mean rate $(+23 \%)$ as did patients who regulated their training intensity using heart rate reserve (70\% HRR: $+34 \%)$ or both HRR and perceived exertion (60-80\% of HRR and "slightly strenuous": $+31 \%$; Ilarraza et al., 2004).

\section{Minimizing health risks}

Exercise therapy usually requires a systematic screening of the individual risk related to physical activity and, when indicated, a (sports) medical risk stratification. In cardiac prevention and rehabilitation, based on many years of clinical experience and numerous studies, eligible groups of patients have been identified who may regulate their training using sense of exertion. According to the guideline on physical activity in the secondary prevention of cardiovascular diseases of the German Society of Prevention and Rehabilitation of Heart and Circulatory Diseases (DGPR), persons at risk level "A"-which includes children, men $<45$ years, and women $<55$ years without symptoms of heart disease and without main risk factors-do not require monitoring of the heart rate during exercise training. For patients at risk level "B"- which involves stable cardiovascular disease and a low risk of complications during higher physical stress-instrument-based monitoring of the exercise and supervision by a physician is only recommended if the disease has recently been diagnosed and if the estimation of exercise tolerance does not seem reliable (Bjarnason-Wehrens et al., 2009a).

The DGPR recommends that patients at risk level B use the Borg Scale only in addition to other regulation options and to support learning of the realistic perception of level of exertion (BjarnasonWehrens et al., 2009a). This is because the Borg Scale as a single regulatory parameter can be subject to interfering factors such as sense of self, body perception, ambition, and group dynamics.

In contrast, the ACSM recommends use of only the Borg Scale if no recent re- sult of an exercise stress test is available (American College of Sports Medicine et al., 2010). In fact, in routine health care, intensity is often regulated by perceived exertion. In Australia, 80\% of cardiac rehabilitation centers use the BorgRPE, and only $19 \%$ use heart rate or the results of an exercise performance stress test (Abell, Glasziou, Briffa, \& Hoffmann, 2016).

\section{Positive affective response}

Affective responses during or after physical activity are usually described alongside basic affective dimensions (Schimmack \& Grob, 2000). The circumplex model of emotion (Ekkekakis, 2008) is widely used, which includes a dimension of affective valence (bad vs. good feeling; discomfort vs. well-being) and, largely independent of this, a dimension of arousal (awake, highly aroused vs. sparsely aroused). In some instances, the latter dimension is differentiated according to whether it is a positive activation (e.g., full of energy vs. de-energized) or a negative activation (agitated vs. calm).

Affective responses were first included in the 2011 ACSM training recommendations for healthy adults (Garber et al., 2011). A major reason for their inclusion is that positive affective reactions (e.g., positive valence and high positive arousal) are associated with the maintenance of sports activity, with the affective response during the activity being especially important (Rhodes \& Kates, 2015). Additionally, in training recommendations, affective responses have been discussed as secondary methods of regulating exercise intensity, since there are systematic relations with physiological threshold concepts (Ekkekakis \& Acevedo, 2006).

In the context of exercise regulation, several studies indicate that self-chosen intensities are associated with more positive affective responses than predetermined exercise intensities are, even if the objectively measured intensity is comparable. This may partly be explained by the higher feeling of autonomy of the exercising person (Ekkekakis, 2009; Parfitt, Rose, \& Burgess, 2006). 
Table 1 Typical elements of approaches to promote the acquirement of control competency

General information on effective and safe exercise intensities and durations in endurance training

Theoretical instruction and successive practical exercise on how to regulate exercise intensity

On the basis of breathing or a talk test: participants should be able to talk reasonably well during exercise

With a heart rate monitor (as far as the medication allows for that): at $40-60 \%$ heart rate reserve (Karvonen formula)

Using subjective rating of perceived exertion (Borg scale): usually aiming at Borg 11-14

Considering subjective signs of a high training stress (e. g., deteriorated coordination)

Using structured assessments of the affective condition (e. g., the Feeling Scale or its German translation)

Introduction to general pacing strategy

Aim for an even performance (i. e., speed or power output)

When in doubt, aim for a negative pacing strategy (slightly slower start, then gradual increase of intensity throughout the training bout)

Performing simple endurance activities at safe intensity domains while being supported by an exercise trainer or therapist and by monitoring of objective parameters

Autonomous monitoring and documentation of training

\section{Table 2 Core elements of a specific training to promote the learning of pacing}

Fostering and amplifying the feed-forward and feedback elements of pacing

Estimating the momentary performance (speed or power output) without external cues: who can estimate the best?

Estimating of own heart rate without looking at the heart rate monitor: who is the closest?

Early estimation of the perceived exertion that should occur at the end of the training if the current chosen or prescribed intensity is being held constant

Early estimation of the distance/time for which a certain intensity can be held constant without overly high exertion

Securing the relation with objective information and increasing variation

Variation of feedback: pacing without monitoring the heart rate, without immediate support by the therapist

Variation of activities: pacing in walking vs. pacing on a cycle ergometer

Small variation of environmental conditions: walk uphill, exercise at slightly varying environmental temperatures

Strongly varying or more difficult conditions

Training with persons or groups of differing performance. Patients and clients should be able to recognize early that a certain speed of the training partner or group is too high or too low and should be able to choose their own speed or decide early to adjust training length accordingly

Training with activating or calming/relaxing music

Experiencing the physiological and affective responses to variations of pacing (positive, even, negative)

Trying out the immediate effects of intensities below and above conventional training prescriptions for a restricted time

Testing the immediate effects of exercise of considerably longer duration

Throughout the learning of pacing, participants need to be thoroughly informed about the nature of this training and consequentially about their role and self-responsibility. Exercise trainers and therapists should always carefully consider and, if necessary, clarify whether each individual participant is adequately prepared as well as whether the use of a certain training element is without unnecessary risks and medically indicated

\section{Learning of pacing for the acquisition of control competence}

\section{Practice}

Control competence far exceeds the ability to mechanistically exercise at a predetermined rating of perceived exertion (e.g., "Borg 13"). Approaches to promoting acquaintance with control competency can be found, for example, in the German programs of heart schools (Höner, Sudeck, Keck, \& Kosmützky, 2011), obesity school manuals (Stachow \& Flothkötter, 2004), and school concepts for a healthy back (Pfeifer, 2007). These programs address the perception of physical stress and the various possibilities to self-regulate endurance performance. Apart from information on the regulation of performance (lectures, group discussions), they also offer practical forms of exercise for walking and walking technique. Methodologically, one may start with intermittent exercise, followed by a stepwise prolongation of intervals and shortening of breaks until continuous exercise is possible. Typical elements for a person with ischemic heart disease are displayed in - Table 1.

As described above, pacing involves keeping or changing the speed or power output based on, among other things, the anticipation of remaining work, the perception of effort, and the comparison of this perception with previous experience. These components, which effectively constitute pacing, are already employed in various ways by experienced health sports participants and patients as well as by exercise assistants and therapists. Implicitly and explicitly, they are included in existing concepts (Höner et al., 2011; Pfeifer, 2007). Core elements of a specific "pacing training" include variation in training intensity, partly variation in training length, and-under defined circumstances-playing with pacing or its constituents (๑ Table 2).

\section{Evidence base}

Scientific studies addressing the question of how to best promote the learning 
of pacing are scarce. It seems undeniable that, depending on intensity, focusing the attention on internal (i.e., the own body) or external processes (i. e., the environment) can have positive or negative effects on the perception of effort and running economy (Lind, Welch, \& Ekkekakis, 2009; Schücker, Knopf, Strauss, \& Hagemann, 2014). Dissociative strategies (attempts at selfdistraction, i. e., focusing on other things than the perception of physical stress) may reduce the perception of effort and improve affective response at low to moderate intensities. At high intensities, because of the dominance of physiological signals, they are no longer effective (Ekkekakis et al., 2011; Lind et al., 2009).

Accordingly, dissociative strategies and factors like targeted music might be used during moderate intensity exercise to improve participation motivation and adherence (Karageorghis, Terry, Lane, Bishop, \& Priest, 2012; Lind et al., 2009). Conversely, associative strategies (to consciously shift the focus to the perception of physical effort) may help mitigate the risks related to overly high exercise intensity (Lind et al., 2009). Further, associative strategies might be advantageous in enhancing the self-estimation of stress as a prerequisite for the adequate self-regulation of physical performance.

Concerning the question of which population is able to well estimate their physical stress and effectively regulate their performance, initial findings have been partially contradictory. In a heterogeneous sample of over 2500 persons, Scherr and colleagues observed that the relations between RPE and heart rate $(r=0.74)$ and between RPE and blood lactic acid level $(r=0.83)$ are not systematically influenced by age, gender, the presentation of coronary heart disease, the physical activity level, or the mode of the exercise test (Scherr et al., 2013). In contrast, another group reports that women tend to overestimate, and regularly exercising persons tend to underestimate, their exercise stress (Skatrud-Mickelson, Benson, Hannon, \& Askew, 2011).

Independent of the selective targeting of a specific level of effort, patients seem to intuitively align their free self-regulation of performance to disease-specific organic and functional alterations. The majority of patients with congestive heart failure seems to choose their gait speed in a manner which ensures a low ventilatory cost (low ventilatory equivalent for carbon dioxide), whereas healthy persons rather aim to minimize energetic cost (Figueiredo, Ribeiro, Bona, PeyréTartaruga, \& Ribeiro, 2013).

Pacing might also offer opportunities to make control competency measurable in the field and thereby accessible to evidence basing, providing exercising persons with an option to self-estimate their control competency. On a behavioral level, control competency can thus be expressed as follows:

- rapidly finding an individually adequate speed or exercise intensity to cover a defined distance;

- evenly keeping a high pace over a defined time (e.g., six-minute walking test);

- swiftly recognizing an individually non-appropriate intensity (e.g., when exercising with a very well performing group); and

- reliably choosing a preferred or prescribed speed or exercise intensity under systematically varying conditions.

\section{Side effects and potential of self-regulated exercise training in health sports}

If exercisers take greater responsibility for regulating their training load, some will exercise less and others more intensively than recommended. In this respect, before starting an exercise program, it is necessary to identify persons with contraindications (physical activity questionnaire, sports medical examination) and persons who need special support (e.g., no previous experience with sports training). The latter usually have to be instructed, guided, and coached more intensely. Apart from studies with very small samples, in which no side effects were observed during self-regulated exercise (Ilarraza et al., 2004), it is unclear how far self-regulation alters the risk for side effects. Both increased as well as decreased risk seems plausible, depending on the control competency and the respective conditions. The absolute risk of a cardiac complication during physical training is generally very low, with 0.08 to 0.24 incidents per 10,000 training hours, and it is quite similar for patients in cardiac outpatient rehabilitation and healthy persons doing leisure sports (Foster \& Porcari, 2001). The relative risk of an immediate cardiac event during physical training (as compared to being sedentary) lies between 2.1 and 56 (Franklin \& Billecke, 2012). Physically inactive individuals with cardiovascular disease who perform high intensity work that they are not used to have the highest relative risk (Foster \& Porcari, 2001; Franklin \& Billecke, 2012). These individuals should increase their training load very carefully over a long period of time and should be educated concerning load regulation with special diligence.

Under certain premises, in some patient groups, the use of high intensity training (HIT) is considered effective and safe (Guiraud et al., 2012; Helgerud et al., 2011). Preliminary studies showed that during or immediately after a total of $46,000 \mathrm{~h}$ of supervised intensive interval exercise, two non-lethal cardiac events (cardiac arrests) occurred, and one event occurred during $129,000 \mathrm{~h}$ of moderate intensity training (Rognmo et al., 2012). The data are still far from sufficient to make a safe statement concerning the long-term effects and risks of high intensity training. Yet, they indicate that higher exercise intensities (which may occur more frequently during self-regulated exercise) are not inevitably associated with high risks. Focusing on the affective response, however, it has to be considered to which extent higher intensities may be associated with negative side effects on adherence, especially in persons with limited exercise experience (Decker \& Ekkekakis, 2017).

If pacing and load regulation is viewed as outlined here, this also has implications in the role of monitoring training load and the response to this load. Instead of a permanent verification of whether exercise is being done within the desired ("correct") intensity range, characteristics of load (e.g., speed) and stress (e.g., 
heart rate) can be regarded as feedback to educate an individual's own perception during a learning process. Information and communication technologies that allow the direct display, processing, and communication of field-registered signals, indicators of performance, and subjective parameters (Meißner, 2012) may simplify this learning process. Such technology can include accelerometers, pedometers, GPS systems, dynamometers, and heart rate monitors, as well as successive registrations of perceived exertion and affective response. Telemetry enables therapists and physicians to monitor and support the process of learning pacing from a distance.

Patient orientation and the promotion of self-determined and competent participation are pivotal elements of modern approaches to rehabilitation. They are especially challenging in patients who are unsettled because of physical deconditioning and who have to (re-)learn the handling and estimation of physical load. If, step by step, patients are empowered to (co-)regulate their exercise, they will even more become co-producers of their own health and well-being. Increasingly, they will become organizationally independent and will be able to use more diverse exercise offers, which can promote motivation and compliance.

\section{Conclusion and outlook}

Pacing is the fundamental mechanism of regulating physical performance. It is based on the perception of effort and further includes the choice or preference of a level of exertion, anticipation of remaining physical work, estimation of the current physical capacity, consideration of past experience, and, building on this, perpetuation or alteration of the momentary physical work rate.

The scientific discussion and examination of pacing offers valuable links for exercise regulation in health sports and exercise therapy in order to do the following:

- substantiate existing concepts for the promotion of the subordinate aim of "control competency" as a component of physical-activityrelated health competence;
- correspondingly broaden practical approaches of its promotion; and

- make control competency measurable in the field.

Several related aspects have already been considered in exercise therapy programs and can be found in the target setting of the German classification of therapeutic services (KTL, DRV, 2015). The potential benefits of a stronger consideration of pacing seem great, and pacing to promote control competency therefore is important in research on sports for health and on exercise therapy. Such research is fundamental for the physiological as well as pedagogic-psychological foundation of sports for health and exercise therapy.

For research on target-group-specific opportunities and limitations of the self-regulation of physical/sports load, all three target levels of control competency-optimizing of health effects, minimizing of health risks, and inducing positive affective responses-should be considered. In addition to models of the fatigue-mediated regulation of physical work rate and analyses of pacing profiles in health sports contexts, research on the freely chosen speed of walking and running (Ekkekakis, 2009) and on the correlation between exercise intensity and affective condition (Ekkekakis et al., 2011) provides a basis and inspiration for further studies.

Currently, relatively little is known about how everyday work regulation actually takes place. We need a better understanding of the physiological regulation mechanisms and conditions favorable for perception and learning in specific target groups. This would make it easier to identify populations suitable for self-regulation as well as to advance interventions that improve the perception of stress and the effective self-regulation of exercise loads (Ekkekakis, 2009). Based on this, it remains to be seen in controlled studies if and which feedback on the objective stress under varying load conditions best enables exercising persons to optimally educate and calibrate their control competency.

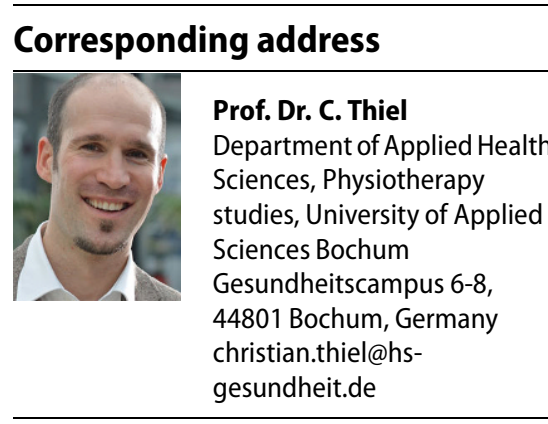

Conflict of interest. C. Thiel, K. Pfeifer and G. Sudeck declare that they have no competing interests.

Open Access This article is distributed under the terms of the Creative Commons Attribution 4.0 International License (http://creativecommons.org/licenses/by/ 4.0/), which permits unrestricted use, distribution, and reproduction in any medium, provided you give appropriate credit to the original author(s) and the source, provide a link to the Creative Commons license, and indicate if changes were made.

\section{References}

Abbiss, C. R., \& Laursen, P. B. (2008). Describing and understanding pacing strategies during athletic competition. Sports Medicine, 38(3), 239-252.

Abell, B., Glasziou, P., Briffa, T., \& Hoffmann, T. (2016). Exercise training characteristics in cardiac rehabilitation programmes: a crosssectional survey of Australian practice. Open Heart, 3(1), e374.

American College of Sports Medicine, Thompson, W. R. Gordon, N. F., \& Pescatello, L. S. (2010). ACSM's guidelines for exercise testing and prescription (8th edn.). Philadelphia: Lippincott Williams \& Wilkins, Wolters Kluwer Health.

Baron, B., Moullan, F., Deruelle, F., \& Noakes, T. D. (2011). The role of emotions on pacing strategies and performance in middle and long duration sport events. British Journal of Sports Medicine, 45(6), 511-517.

Bernard, T., Hausswirth, C., Le Meur, Y., Bignet, F., Dorel, S., \& Brisswalter, J. (2009). Distribution of power output during the cycling stage of a Triathlon World Cup. Medicine and Science in Sports and Exercise, 41(6), 1296-1302.

Bjarnason-Wehrens, B., Schulz, O., Gielen, S., Halle, M., Dürsch, M., \& Hambrecht, R. (2009a). Leitlinie körperliche Aktivität zur Sekundärprävention und Therapie kardiovaskulärer Erkrankungen. Clinical Research in Cardiology Supplements, 4(S3), 1-44.

Bjarnason-Wehrens, B., Schulz, O., Gielen, S., Halle, M., Dürsch, M., \& Hambrecht, R. (2009b). Leitlinie körperliche Aktivität zur Sekundärprävention und Therapie kardiovaskulärer Erkrankungen. Clinical Research in Cardiology, 98(Suppl 3), 1-44. http://www.dgpr.de/fileadmin/user_upload/ DGPR/Leitlinien/LL_Koerperliche_Aktivitaet_ CRCS078.PDF.

Borg, G. (1970). Perceived exertion as an indicator of somatic stress. Scandinavian Journal of Rehabilitation Medicine, 2(2), 92-98.

Burschka, J. M., Keune, P. M., Menge, U., Hofstadt-van Oy, U., Oschmann, P., \& Hoos, O. (2012). An exploration of impaired walking dynamics and 
fatigue in multiple sclerosis. BMC Neurology, 12, 161.

Castro, A. A. M., Porto, E. F., lamonti, V. C., de Souza, G. F., Nascimento, O. A., \& Jardim, J. R. (2013). Oxygen and ventilatory output during several activities of daily living performed by COPD patients stratified according to disease severity. PloS one, 8(11), e79727.

Davis, J. M., \& Bailey, S. P. (1997). Possible mechanisms of central nervous system fatigue during exercise. Medicine and Science in Sports and Exercise, 29(1), 45-57.

Decker, E. S., \& Ekkekakis, P. (2017). More efficient, perhaps, but at what price?: Pleasure and enjoyment responses to high-intensity interval exercise in low-active women with obesity. Psychology of Sport and Exercise, 28, 1-10.

Deutsche Rentenversicherung (2016). Reha-Therapiestandards Koronare Herzkrankheit: für die medizinische Rehabilitation der Rentenversicherung. http://www.deutsche-rentenversicherung.de/ Allgemein/de/Inhalt/3_Infos_fuer_Experten/ 01_sozialmedizin_forschung/downloads/ quali_rehatherapiestandards/KHK/rts_khk download.html. Accessed 1. July 2017

Edwards, A. M., \& Polman, R. C. J. (2013). Pacing and awareness: brain regulation of physical activity. Sports Medicine, 43(11), 1057-1064.

Ekkekakis, P. (2008). Affect circumplex redux: the discussion on its utility as a measurement framework in exercise psychology continues. International Review of Sport and Exercise Psychology, 1(2), 139-159.

Ekkekakis, P. (2009). Let them roam free? Physiological and psychological evidence for the potential of self-selected exercise intensity in public health. Sports Medicine, 39(10), 857-888.

Ekkekakis, P., \& Acevedo, E. O. (2006). Affective responses to acute exercise: toward a psychobiological dose-response model. In E. O. Acevedo \& P. Ekkekakis (Eds.), Psychobiology of physical activity (pp. 91-109). Champaign: Human Kinetics.

Ekkekakis, P., Parfitt, G., \& Petruzzello, S.J. (2011). The pleasure and displeasure people feel when they exercise at different intensities: decennial update and progress towards a tripartite rationale for exercise intensity prescription. Sports Medicine, 41(8), 641-671.

Enoka, R. M., \& Duchateau, J. (2008). Muscle fatigue: what, why and howitinfluencesmusclefunction. The Journal of Physiology, 586(1), 11-23.

Faulkner, J., Parfitt, G., \& Eston, R. (2008). The rating of perceived exertion during competitive running scales with time. Psychophysiology, 45(6), 977-985.

Figueiredo, P., Ribeiro, P.A.B., Bona, R.L., PeyréTartaruga, L. A., \& Ribeiro, J. P. (2013). Ventilatory determinants of self-selected walking speed in chronic heart failure. Medicine and Science in Sports and Exercise, 45(3), 415-419.

Foster, C., \& Porcari, J.P. (2001). The risks of exercise training. Journal of Cardiopulmonary Rehabilitation, 21(6), 347-352.

Franklin, B. A., \& Billecke, S. (2012). Putting the benefits and risks of aerobic exercise in perspective. Current Sports Medicine Reports, 11(4), 201-208.

Garber, C. E., Blissmer, B., Deschenes, M. R., Franklin, B. A., Lamonte, M.J., \& Lee, I.-M. (2011) American College of Sports Medicine position stand. Quantity and quality of exercise for developing and maintaining cardiorespiratory, musculoskeletal, and neuromotor fitness in apparently healthy adults: guidance for prescribing exercise. Medicine and Science in Sports and Exercise, 43(7), 1334-1359.

Guiraud, T., Nigam, A., Gremeaux, V., Meyer, P. Juneau, M., \& Bosquet, L. (2012). High-intensity interval training in cardiac rehabilitation. Sports Medicine, 42(7), 587-605.

Hansen, D., Dendale, P., Berger, J., \& Meeusen, R. (2005). Rehabilitation in cardiac patients:what do we know about training modalities? Sports Medicine, 35(12), 1063-1084.

Helgerud, J., Karlsen, T., Kim, W. Y., Høydal, K. L., Støylen, A., \& Pedersen, H. (2011). Interval and strength training in CAD patients. International Journal of Sports Medicine, 32(1), 54-59.

Höner, O., Sudeck, G., Keck, M., \& Kosmützky, G. (2011). Verhaltensbezogene Interventionen in derSport-und Bewegungstherapie. Bewegungs therapie \& Gesundheitssport, 27(3), 111-120.

llarraza, H., Myers, J., Kottman, W., Rickli, H., \& Dubach, P. (2004). An evaluation of training responses using self-regulation in a residential rehabilitation program. Journal of Cardiopulmonary Rehabilitation, 24(1), 27-33.

Jones, H. S., Williams, E. L., Bridge, C. A., Marchant, D., Midgley, A. W., Micklewright, D., \& Mc Naughton, L. R. (2013). Physiological and psychological effects of deception on pacing strategy and performance: a review. Sports Medicine, 43(12) $1243-1257$

Karageorghis, C. I., Terry, P. C., Lane, A. M., Bishop, D. T., \& Priest, D. (2012). The BASES Expert Statemen on use of music in exercise. Journal of Sports Sciences, 30(9), 953-956.

Knicker, A. J., Renshaw, I., Oldham, A. R. H., \& Cairns, S. P. (2011). Interactive processes link the multiple symptoms offatigue in sport competition. Sports Medicine, 41(4), 307-328.

Lind, E., Welch, A. S., \& Ekkekakis, P. (2009). Do 'mind over muscle' strategies work? Examining the effects of attentional association and dissociation on exertional, affective and physiological responses to exercise. Sports Medicine, 39(9), 743-764.

March, D.S., Vanderburgh, P.M., Titlebaum, P.J., \& Hoops, M. L. (2011). Age, sex, and finish time as determinants of pacing in the marathon. Journal of Strength and Conditioning Research, 25(2), 386-391.

Meißner, F. (2012). Telematik im Gesundheitswesen: Von der Integrierten Versorgung bis zum Facebook für Kranke. Bewegungstherapie \& Gesundheitssport, 28(4), 154-159.

Le Meur, Y., Hausswirth, C., Dorel, S., Bignet, F., Brisswalter, J., \& Bernard, T. (2009). Influence of gender on pacing adopted by elite triathletes during a competition. European Journal of Applied Physiology, 106(4), 535-545.

Parfitt, G., Rose, E.A., \& Burgess, W.M. (2006). The psychological and physiological responses of sedentary individuals to prescribed and preferred intensity exercise. British Journal of Health Psychology, 11(Pt 1), 39-53.

Pfeifer, K. (2007). Rückengesundheit: Grundlagen und Module zur Planung von Kursen. Köln: Deutsche Ärzte-Verlag.

Rhodes, R.E., \& Kates, A. (2015). Can the affective response to exercise predict future motives and physical activity behavior? A systematic review of published evidence. Annals of Behavioral Medicine: a Publication of the Society of Behavioral Medicine, 49(5), 715-731.

Roelands, B., de Koning, J.J., Foster, C., Hettinga, F., \& Meeusen, R. (2013). Neurophysiological determinants of theoretical concepts and mechanisms involved in pacing. Sports Medicine, 43(5), 301-311.

Rognmo, Ø., Moholdt, T., Bakken, H., Hole, T., Mølstad, P., Myhr, N. E., et al. (2012). Cardiovascular risk of high-versus moderate-intensity aerobic exercise in coronary heart disease patients. Circulation, 126(12), 1436-1440.

Scherr, J., Wolfarth, B., Christle, J.W., Pressler, A., Wagenpfeil, S., \& Halle, M. (2013). Associations between Borg's rating of perceived exertion and physiological measures of exercise intensity. European Journal of Applied Physiology, 113(1), 147-155.

Schimmack, U., \& Grob, A. (2000). Dimensional models of core affect: a quantitative comparison by means of structural equation modeling. European Journal of Personality, 14(4), 325-345.

Schücker, L., Knopf, C., Strauss, B., \& Hagemann, N. (2014). An internal focus of attention is not always as bad as its reputation: how specific aspects of internally focused attention do not hinder running efficiency. Journal of Sport \& Exercise Psychology, 36(3), 233-243.

Skatrud-Mickelson, M., Benson, J., Hannon, J.C., \& Askew, E. W. (2011). A comparison of subjective and objective measures of physical exertion. Journal of Sports Sciences, 29(15), 1635-1644.

Smits, B. L. M., Pepping, G.-J., \& Hettinga, F. J. (2014). Pacing and decision making in sport and exercise: the roles of perception and action in the regulation of exercise intensity. Sports Medicine, 44(6), 763-775.

St Clair Gibson, A., Lambert, E. V., Rauch, L. H. G., Tucker, R., Baden, D. A., Foster, C., \& Noakes, T. D. (2006). The role of information processing between the brain and peripheral physiological systems in pacing and perception of effort. Sports Medicine, 36(8), 705-722.

St Clair Gibson, A., de Koning, J. J., Thompson, K. G. Roberts, W. O., Micklewright, D., Raglin, J., \& Foster, C. (2013). Crawling to the finish line: why do endurance runners collapse? Implications for understanding of mechanisms underlying pacing and fatigue. Sports Medicine, 43(6), 413-424.

Stachow, R., \& Flothkötter, M. (2004). Trainermanual leichter, aktiver, gesünder: Interdisziplinäres Konzept für die Schulung übergewichtiger oder adipöser Kinder und Jugendlicher. Vol. 3842. Bonn: AID-Infodienst Verbraucherschutz, Ernährung, Landwirtschafte.V.

Sudeck, G., \& Pfeifer, K. (2016). Physical activityrelated health competence as an integrative objective in exercise therapy and health sports: conception and validation of a short questionnaire. Sportwissenschaft, 46(2), 74-87.

Thiel, C., Foster, C., Banzer, W., \& de Koning, J. J. (2012). Pacing in olympictrack races: competitive tactics versus best performance strategy. Journal of Sports Sciences, 30(11), 1107-1115.

Thiel, C., Vogt, L., \& Banzer, W. (2012). Narrative Übersicht zur Bewegungsdosis in Prävention und Therapie. Bewegungstherapie \& Gesundheitssport, 28(1), 43-46.

Thiel, C., de Koning, J., \& Foster, C. (2015). Potenzielle Einflussfaktoren auf Pacing im ausdauersportlichen Wettkampf. Sportwissenschaft, 45(4), 173-189.

Timmons, J. A. (2011). Variability in training-induced skeletal muscle adaptation. Journal of Applied Physiology, 110(3), 846-853.

Tucker, R. (2009). The anticipatory regulation of performance: the physiological basis for pacing strategies and the development of a perception- 


\section{Discussion}

based model for exercise performance. British Journal of Sports Medicine, 43(6), 392-400.

Tucker, R., Lambert, M.I., \& Noakes, T.D. (2006). An analysis of pacing strategies during men's world-record performances in track athletics. International Journal of Sports Physiology and Performance, 1(3), 233-245.

Ulmer, H. V. (1996). Concept of an extracellular regulation of muscular metabolic rate during heavy exercise in humans by psychophysiological feedback. Experientia, 52(5), 416-420.

Weir, J. P., Beck, T. W., Cramer, J. T., \& Housh, T. J. (2006). Is fatigue all in your head? A critical review of the central governor model. British Journal of Sports Medicine, 40(7), 573-586. 